Christic, M. J., and Venables, P. II. (1971). Effects on 'basal" skin potential level of varying the concentration of an exicrnal electrolytc. Journal of Psychosomatic Research. (In press.)

Darrow, C. W. (1932). The relation of the galvanic skin reflex recovery curve to reactivity, resistance level, and perspiration. Journal of General Psychology, 7, 261-266.

Douglas, R. J. (1967). The hippocampus and behaviour. Psychological Bulletin, 67, 416-442.

Dykman, R. A., Reese, W. G., Galbrecht, C. R., Ackerman, P. T., and Sunderman, R. S. (1968). Autonomic responses in psychiatric patients. Annals of the New York Academy of Sciences, 147, 237-303.

Edelberg, R. (1970). The information content of the recovery limb of the electrodermal response. Psychophysiology, 6, 527-539.

Fowles, D. C., and Venables, P. H. (1968). Endocrine factors in palmar skin potential. Psychonomic Science, 10, 387-388.

Fowles, D. C., and Venables, P. H. (1970). The effects of epidermal hydration and sodium reabsorption on palmar skin potential. Psychological Bulletin, 73, 363-378.

Graham, F. K., and Clifton, R. K. (1966). Heart rate change as a component of the orienting response. Psychological Bulletin, 65, 304-320.

Grastayan, E., Karmos, G., Vereczkey, L., and Kellenyi, E. E. (1966). The hippocampal electrical correlates of the homeostatic regulation of motivation. Electroencephalography and Clinical Neurophysiology, 21, 34-53.

Gruzelier, J. H. (1970). A switch process in schizophrenia? Paper presented to the British Psychological Society, December 1970.

Kimble, D. P. (1968). Hippocampus and internal inhibition. Psychological Bulletin, 70, 285-295.

Lacey, J. I., and Lacey, B. C. (1970). Some autonomic-central nervous system inter-relationships, in Physiological Correlates of Emotion. Edited by P. Black. Academic Press: New York.
Lader, M. H., and Wing, L. (1906). Phisiological Mrasures, Sedative Drugs, and Morbid Anxisty. O.U.P'.: London.

L.ynn, R. (1966). Altemion, Arotasal and the Oricontrion Réciction. Pergamon: Oxford.

Maclean, P. D. (1970). The limbic brain in relation to the psychoses, in Physiological Correlates of Emotion. Edited by P. Black. Academic Press: New York.

Mednick, S. A., and Schulsinger, F. (1968). Some pre-morbid characteristics related to breakdown in children with schizophrenic mothers, in The Transmission of Schizophrenia. Edited by D. Rosenthat and S. S. Kety. Pergamon: Oxford.

Obrist, P. A., Webb, R. A., Sutterer, J. R., and Howard, J. L. (1970). Cardiac deceleration and reaction time: an evaluation of two hypotheses. Psychophysiology, 6, 695-706.

Sanwald, J. C., Porzio, N. R., Deane, G. E., and Donovick, P. J. (1970). The effects of septal and dorsal hippocampal lesions on the cardiac component of the orienting response. Physiology and Behaviour, 5, 883-888.

Stern, J. A. (1964). Toward a definition of psychophysiology. Psychophysiology, 1, 90-91.

Sternbach, R. A. (1966). Principles of Psychopliysiology. Academic Press: New York.

Walter, W. G., Cooper, R., Crow, H. J., McCallum, W. C., Warren, W. J., Aldrige, V. J., Storm van Lecuwen, W., and Kamp, A. (1967). Contingent negative variation and evoked responses recorded by radio-telemetry in free ranging subjects. Electroencephalography and Clinical Neurophysiology, 23, 197-206.

Weiss, B., and Siegel, L. (1967). The laboratory computer in psychophysiology, in Methods in Psychophysiology. Edited by C. C. Brown. Williams and Wilkins: Baltimore.

Zahn, T. P., Rosenthal, D., and Lawlor, W. G. (1968). Electrodermal and heart rate orienting reactions in chronic schizophrenia. Juturnal of Psychiatric Research, 6, 117-134.

\title{
2. How many psychiatric beds?
}

At the end of 1954, there were 150,000 patients in the psychiatric hospitals and units of the United Kingdom-344 for every 100,000 people in the population. This was the turning point. After increasing steadily throughout the century, the number of beds began to go down. On 31 December 1968, there were only 120,000 beds; 248 per 100,000 . Nearly three-quarters of the patients were long-staythat is, they had been resident for more than a year, while just under 70 beds per 100,000 were used by shorter-stay patients (Department of Health and Social Security, 1970). Most attempts to estimate how many beds will be needed in future are grounded partly on the observation of statistical trends and partly on value judgments as to how far the trends should be allowed, or provoked, to go. There is, however, an imponderable factor, concerning the definition of the term 'bed', which must also be considered.

So far as statistical trends in conventional bed numbers are concerned, the calculation has three components: the number of beds at present occupied by patients who have been in hospital longer than a year (the accumulation from the past); the number of beds needed for patients who will become long-stay in the future; and the number of shorter-stay beds.

The first component can be ignored if the estimate is projected sufficiently far ahead, say 25 years, since nearly all the present long-stay patients will by then have died or been discharged. In order to make a satisfactory estimate of the second and third components, it is necessary to have detailed information concerning the age, sex, diagnosis, and length of stay composition of the mental hospital population on annual census days, and long-term follow-up data on cohorts of admissions. National statistics do not yet provide such information. Psychiatric case registers do supply it and useful 
estimales can be derived for local purposes (Baldwin, 1967; Hatley, 1971). At the national level there is still nothing to replace Tooth and Brooke's study (1961), which predicted, on the basis of trends observed over the years 1954 to 1959, that some 180 beds per 100,000 population would eventually be needed. A recent study in Denmark suggests that no greal change should be expected in the overall Danish figure of 219 beds per 100,000 population, even though radical developments are occurring in the psychiatric services, including the introduction of day hospitals and district general hospital units (Juel-Nielsen and Strömgren, 1969). Estimates based on trends in the Scottish figures are also cautious (Baldwin, 1968).

Seen against this statistical background, the latest estimate from the Department of Health and Social Security (1969), of 50 beds per 100,000 population, seems very low, even when allowance is made for the fact that beds for patients with dementia are not included. No details have been published as to how the figure was derived-an omission that ought to be speedily rectified-but it seems likely that statistical projections have been dispensed with altogether in favour of clinical and administrative judgments. Operational criteria (how things are) are replaced by evaluative ones (how things ought to be). This would be a bold and imaginative step if, indeed, the results of the evaluative research now available were taken into account. Planning would become a rational process.

Three factors appear to have been most influential in forming the judgment about numbers of beds. The first is the decision to place patients suffering from dementia under the care of geriatricians in specialized district units. This would be pure gain if it could ever be implemented with adequate provision, though the present state of the geriatric service does not induce optimism. The second is to transfer the remaining short-term beds to psychiatric units in district general hospitals. Since the present admission units are the best equipped and staffed sector of the mental health service, the main advantage would be some decrease in stigma. In certain areas there would be the added advantage of the new unit being within the area it served rather than miles outside it. At present rates, some 50 beds per 100,000 population would be transferred in this way, accounting for all the D.H.S.S. allocation. The figure might well rise because of extra patients attracted to the new service (first admission rates are still increasing) but this could be counter-balanced if more day hospital places were used, as the Department intends. The third factor is the crucial one: the determination to run down and eventually to close most of the large mental hospitals. This involves the assumption that no new long-stay hospital beds will be needed in future. The boldness of this assumption depends upon the definition of the term 'bed'. Only hospital beds are recognized. There is, however, a sinister-sounding phrase about chronically handicapped patients being 'considered in the context of the younger chronic sick', the meaning of which is obscure.

None of the publications of the D.H.S.S., in spite of the combination of health and social welfare within one department, has dealt in any detail with the alternative residential and occupational facilities which would seem to be necessary. No one can be in any doubt that many patients who used to become long-stay still develop chronic handicaps, and that the present community services do not provide adequately for them (Grad and Sainsbury, 1965; Brown, Bone, Dalison, and Wing, 1966). Schizophrenia still remains the most serious problem, although studies which include only firstreferrals will not discover the full extent of the need (Hoenig and Hamilton, 1969). The presence of a small active unit in the centre of its community, staffed by progressive doctors in close touch with local authority services and with day facilities available, cannot prevent a considerable burden being placed on the health, leisure, and finances of families, if sheltered residential and occupational accommodation is not available (Brown, et al., 1966). It is true that many relatives do not complain very much but this does not mean that there is nothing to complain about or that they would not eagerly make use of a better service if a meaningful choice were offered to them (Pringle, 1970).

Studies of hostels (Mountney, 1965; Apte, 1968; Fletcher, 1970) do not suggest that the problems of institutionalism will be solved simply by closing mental hospitals. Institutionalism is not a neurosis; it is a set of attitudes and habits adopted over many years which finally preclude readaptation to everyday social living. Studies of day centres indicate that patients can be just as inactive there as in 
the back wards of mental hospitals. Studies of reception centres indicate what can happen to patients who fall through the community net (Edwards, Williamson, Hawker, Hensman, and Postogan, 1968).

Much of the most promising work on rehabilitation and resettlement and on preventing the accumulation of secondary handicaps by rational prescription of graded social environments has been carried out in mental hospitals, and the basic principles can readily be adapted to conditions outside (Wing, 1970). Several good models exist, such as the family care system in Beilen, Holland, where the patients attend a sheltered workshop during the day and live in supervised lodgings at night (Wing, 1957). The graded series of hostels and workshops found in progressive mental hospitals (Early, 1965; Wing and Brown, 1970), set in grounds where the patient is shielded from public gaze while, at the same time, the front door of the hostel opens on a main street, provides another model (Catterson, Bennett, and Freudenberg, 1963). Local health and welfare authorities have also set up successful schemes in conjunction with hospitals (May and Wright, 1967). The knowledge and experience necessary to create a new type of service for the chronically handicapped is already available and evaluative research is further ahead than in most sociomedical fields.

Thus, of the three important issues raised by the new D.H.S.S. policy-short-stay beds for acutely ill patients, beds for patients with dementia, and sheltered facilities for the 'new long-stay'-the second and the third have obvious priority. A new D.H.S.S. circular, arising out of a decision on area health boards, would provide an opportunity to deal in detail with the way in which new psychogeriatric facilities and new community arrangements for the chronically handicapped should be set up by the health and the social work authorities acting in concert. The term 'bed' would then be used to cover all types of residential accommodation.

If the more restricted and less urgent question of beds in district general hospitals remained the main focus in isolation from the other problems, and if new district units received the largest share of any extra budget, the mental health service would, paradoxically, become more old-fashioned rather than less. A relatively good service for the acutely ill would exist side by side with a secondclass service, or no service at all, for the chronic patient.

J. K. WING

\section{REFERENCES}

Apte, R. Z. (1968). Halfway Houses. Bell: London.

Baldwin, J. (1967). The growth of mental hospitalisation: the S-shaped curve, in New Aspects of the Mental Health Services. Edited by $\mathrm{H}$. Freeman and J. Farndale. Pergamon: London.

Baldwin, J. (1968). How many beds? A critical discussion of some approaches to hospital planning: II. Mental hospitals. Health Bulletin, 26, 1.

Brown, G. W., Bone, M., Dalison, B., and Wing, J. K. (1966). Schizophrenia and Social Care. O.U.P.: London.

Catterson, A., Bennett, D. H., and Freudenberg, R. K. (1963). A survey of long-stay schizophrenics. British Journal of Psychiarry, 109, 750-757.

Department of Health and Social Security (1969). On the State of the Public Health. Report of the Chief Medical Officer, 1968. HMSO: London.

Department of Health and Social Security (1970). Psychiatric Hospital and Units in England and Wales, 1968. Statistical Report Series No. 11. HMSO: London.

Early, D. (1965). Domestic resettlement and economic rehabilitation, in Psychiatric Hospital Care. Edited by $\mathrm{H}$. Freeman. Ballière, Tindall and Cassell: London.

Edwards, G., Williamson, V., Hawker, A., Hensman, C., and Postoyan, S. (1968). Census of a reception centre. British Journal of Psychiatry 114, $1031-1039$.

Fletcher, J. C. (1970). Mental Health Hostels: Progress and Problems. Working Papers No. 2, Aylesbury: Buckinghamshire County Council.
Grad, J., and Sainsbury, P. (1965). An evaluation of the effects of caring for the aged at home, in Psychiatric Disorders in the Aged. World Psychiatric Association: London.

Hailey, A. (1971). Long-stay psychiatric in-patients: a study based on the Camberwell Register. Psychological Medicine, 1, 128-142.

Hoenig, J., and Hamilton, M. (1969). The Desegregation of the Mentally III. Routledge: London.

Juel-Nielsen, N., and Strömgren, E. (1969). Ten Years Later. Munksgaard: Copenhagen.

May, A., and Wright, S. L. (1967). Developing a community mental health service, in New Aspects of the Mental Health Services, op. cit.

Mountney, G. (1965). Local authority psychiatric hostels. British Journal of Psychiatric Social Work, 10, 20-26.

Pringle, J. (1970). Article, 9 May, The Times.

Tooth, G. C., and Brooke, E. M. (1961). Trends in the mental hospital population and their effect on future planning. Lancet, 1, 710-713.

Wing, J. K. (1957). The family care systems in Norway and Holland. Lancet, 2, 884.

Wing, J. K. (1970). Unemployment among chronic psychotic patients in Camberwell: their need for rehabilitation. Proceedings of the Royal Society of Medicine, 63, December, No. 12, 1329-1332.

Wing, J. K., and Brown, G. W. (1970). Institutionalism and Schizophrenia. Cambridge University Press: London. 